\title{
Sea level rise produces abundant organobromines in salt-affected coastal wetlands
}

\section{Joe-Wong ${ }^{1, t *}$, D.R. Schlesinger ${ }^{2 *}$, A.T. Chow ${ }^{3}$, S.C.B. Myneni ${ }^{2}$}

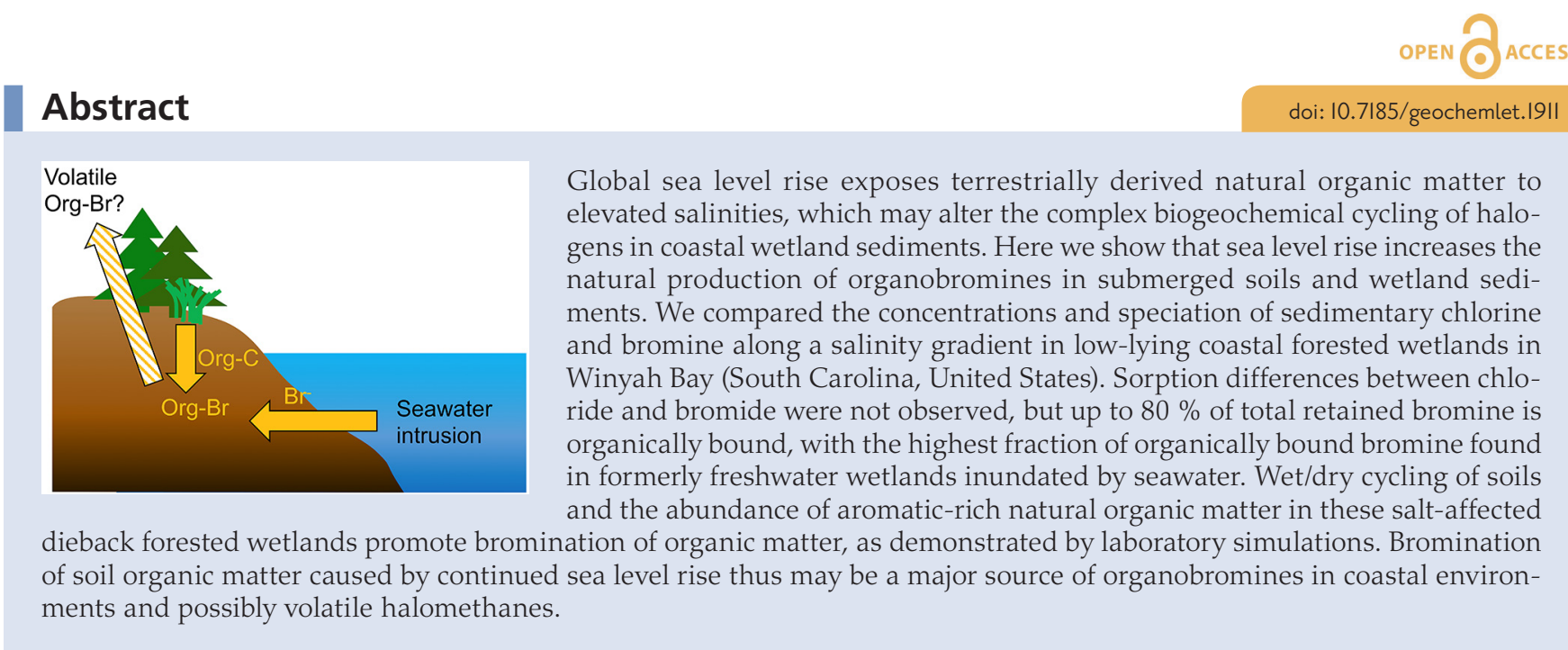

Received 18 January 2019 | Accepted 26 March 2019 | Published 23 April 2019

\section{Introduction}

Global warming and associated rises in sea level threaten to alter the biogeochemistry of coastal ecosystems. Flooding of coastal freshwater wetlands exposes their vegetation and soilbound natural organic matter (NOM) to seawater and ultimately results in conversion to salt marshes (Doyle et al., 2007; Hilton et al., 2008; Krauss et al., 2009). The increased salinity alters the abundance and composition of NOM in salt-affected wetlands (Goñi and Thomas, 2000; Neubauer, 2013), due to changes in vegetal inputs (Tuxen et al., 2011) and microbial activity (Morrissey et al., 2014). Conversely, reactions with previously inaccessible terrestrially derived NOM may also alter the biogeochemical cycling of halogens.

Both chlorine $(\mathrm{Cl})$ and bromine $(\mathrm{Br})$ undergo complex biogeochemical cycling in marine and soil systems. During NOM decomposition, inorganic $\mathrm{Cl}^{-}$and $\mathrm{Br}^{-}$react with NOM both abiotically and biotically to form halogenated organic compounds (organochlorines and organobromines, respectively) (Leri and Myneni, 2010, 2012). Understanding the natural formation of organohalogens is important in order to evaluate the stability of these compounds and their potential breakdown and release as volatile halomethanes. Many halomethanes are known to catalytically destroy stratospheric ozone (Molina and Rowland, 1974), and coastal ecosystems such as salt marshes contribute as much as $10 \%$ of halomethane emissions in the atmosphere (Rhew et al., 2000). It is thus crucial to determine how global sea level rise may affect the biogeochemistry of halogen cycling in coastal ecosystems.

In this study, we evaluate the impacts of seawater intrusion on the production of organohalogens in wetland sediments as a first step towards predicting future halomethane emissions. The study site is located on the southeastern coast of the United States (Winyah Bay, South Carolina, United States) (Fig. S-1) (Titus and Richman, 2001). Winyah Bay is a tidally influenced forest-marsh, backwater-dominated, low-lying wetland ecosystem that has experienced severe saltwater intrusion, successively converting forested freshwater wetland to a salt-affected wetland and salt marsh over a short distance $(\sim 5 \mathrm{~km})$ (Krauss et al., 2009). The freshwater and salt-affected wetlands experience seasonal wet and dry cycles based on precipitation. In contrast, the salt marsh is always saturated, although water depth varies with daily tidal cycles. Vegetation varies significantly with salinity (Krauss et al., 2009; Chow et al., 2013). To assess the importance of NOM origin and composition, we compared the effects of increased salinity on freshwater wetland soils from Winyah Bay and on temperate forest soils from pine lands in New Jersey.

\footnotetext{
1. Department of Chemistry, Princeton University, Princeton, NJ 08544, USA

2. Department of Geosciences, Princeton University, Princeton, NJ 08544, USA

3. Biogeochemistry and Environmental Quality Research Group, Clemson University, Georgetown, SC 29440, USA

Current address: Department of Geological Sciences, Stanford University, Stanford, CA 94305, USA

Corresponding author (email: joewongc@stanford.edu; drs3@princeton.edu)
} 


\section{Methods}

Methodological details are available in the Supplementary Information. In brief, three sites at Winyah Bay spanning a range of salinities were sampled along a transect from the freshwater wetland to the salt-affected wetland and the salt marsh (Fig. S-1). 18-24 cm soil cores were collected between July 2012 and December 2016. At least two cores were taken at each site to assess variability. Additionally, a $30 \mathrm{~cm}$ soil core was collected from the Pine Barrens in New Jersey to determine whether halogenation reactions occur in other ecosystems.

The functional group composition of organic carbon was assessed using Fourier transform infrared (FTIR) spectroscopy and solid state ${ }^{13} \mathrm{C}$ nuclear magnetic resonance (NMR) spectroscopy. $\mathrm{Cl}$ and $\mathrm{Br}$ concentrations and speciation were determined using X-ray fluorescence (XRF) and synchrotron-based 1s X-ray absorption near edge structure (XANES) spectroscopy respectively.

\section{Results and Discussion}

Both the concentrations and the speciation of sediment-bound $\mathrm{Cl}$ and $\mathrm{Br}$ vary between the different sites, as expected. The average concentration of $\mathrm{Cl}\left(\mathrm{Cl}_{\text {total }}\right)$ increases linearly with salinity: from $0.14( \pm 0.07)$ g. $\mathrm{kg}^{-1}$ in freshwater wetland sediments to $6( \pm 1)$ and $27( \pm 2)$ g. $\mathrm{kg}^{-1}$ in the salt-affected wetland and salt marsh, respectively (Table S-1). The variability shown in the parentheses arises from differences between the two sampled cores, which were minimal, and between different depths and seasons. $\mathrm{Cl}$ concentrations decrease with depth in the freshwater and salt-affected wetlands, consistent with soil studies where $\mathrm{Cl}$ concentrations are reported to decrease sharply below the top organic-rich horizons (Leri and Myneni, 2010; Krzmarzick et al., 2012). The absence of such a trend with depth in the salt marsh may be caused by homogenisation via tidal action. The speciation of $\mathrm{Cl}$ also varies with salinity, as shown by $\mathrm{Cl}$ XANES spectroscopy (Fig. 1). Most $\mathrm{Cl}$ in the top layers of freshwater sediments is organically bound $\left(\mathrm{Cl}_{\mathrm{org}}\right)$, although $\mathrm{Cl}$ speciation in the lower layers $(>\sim 14 \mathrm{~cm})$ could not be determined due to the low concentration of $\mathrm{Cl}$. In contrast, salt-affected wetland and salt marsh samples at all depths show predominantly inorganic $\mathrm{Cl}^{-}$(Fig. 1). The presence of $\mathrm{Cl}_{\text {org }}$ cannot be ruled out in the latter samples but is expected to be less than $6 \%$ of $\mathrm{Cl}_{\text {total }}$ (Leri et al., 2006). Variability in $\mathrm{Cl}$ speciation between the two cores collected at each site was also minimal

The abundance and speciation of Br significantly differ from the behaviour of $\mathrm{Cl}$. Total $\mathrm{Br}$ concentrations $\left(\mathrm{Br}_{\text {total }}\right)$ averaged over depth and between two separately collected cores increase from $13( \pm 10) \mathrm{mg} \cdot \mathrm{kg}^{-1}$ in the freshwater wetland to 120 $( \pm 50)$ in the salt-affected wetland but increase only marginally to $160( \pm 14) \mathrm{mg} \cdot \mathrm{kg}^{-1}$ in the salt marsh despite the roughly threefold increase in water salinity. Similar to $\mathrm{Cl}$, most $\mathrm{Br}$ in the freshwater sediments is in the form of organically bound $\mathrm{Br}\left(\mathrm{Br}_{\mathrm{org}}\right)$ (Fig. 2, Table S-1), although variations between wet and dry seasons are observed (Fig. S-3), which may be due to both temporal and spatial heterogeneity. More than $80 \%$ of $\mathrm{Br}$ in the salt-affected wetland and $50 \%$ of $\mathrm{Br}$ in the salt marsh is present as $\mathrm{Br}_{\text {org }}$, in contrast to the predominance of inorganic $\mathrm{Cl}^{-}$at these two sites.

The large difference in $\mathrm{Br}: \mathrm{Cl}$ ratios for seawater and sediments is striking. $\mathrm{Br}: \mathrm{Cl}$ ratios in all sediments are greater than the $\mathrm{Br}: \mathrm{Cl}$ ratio in seawater by a factor ranging from a maximum of 26.5 in the freshwater wetland to a minimum of 1.5 in the salt marsh. $\mathrm{Cl}^{-}$and $\mathrm{Br}^{-}$ions are considered inert and
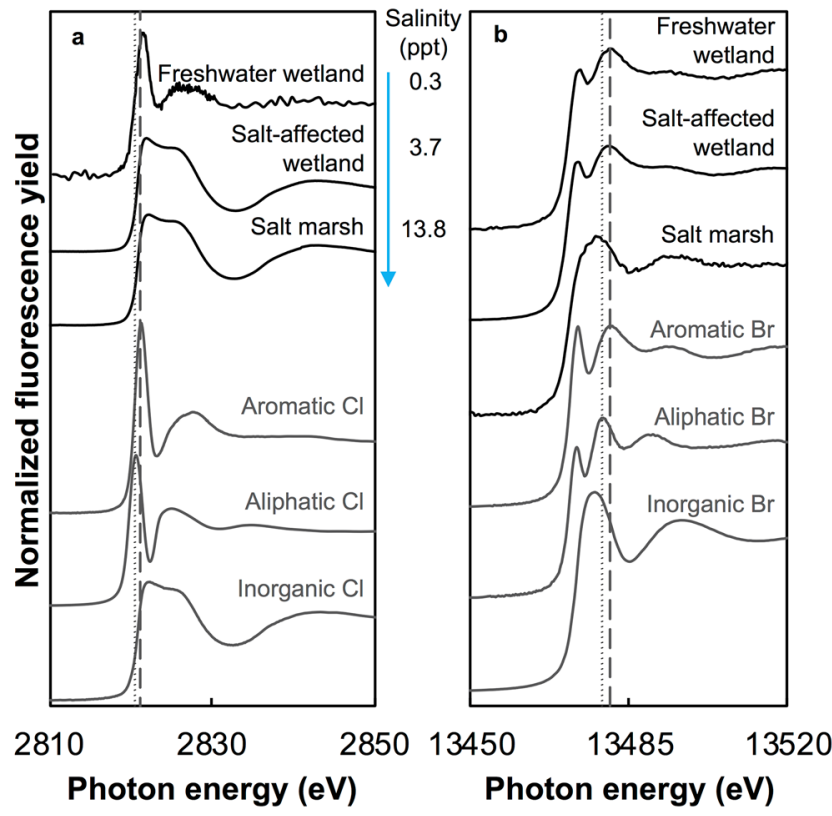

Figure 1 (a) $\mathrm{Cl}$ and (b) $\mathrm{Br}$ XANES spectra of top layer of sediments $(\sim 0-4 \mathrm{~cm})$ on top (black) and standards (grey) at the bottom. Cl standards are chlorophenol red, chlorodecane, and $\mathrm{NaCl}$ (aq) for aromatic, aliphatic, and inorganic $\mathrm{Cl}$ respectively. $\mathrm{Br}$ standards are bromophenol blue, 1-bromoeicosane, and $\mathrm{KBr}$ for aromatic, aliphatic, and inorganic $\mathrm{Br}$ respectively. Grey dotted and dashed lines show the spectral maxima for aliphatic and aromatic organohalogen standards respectively.

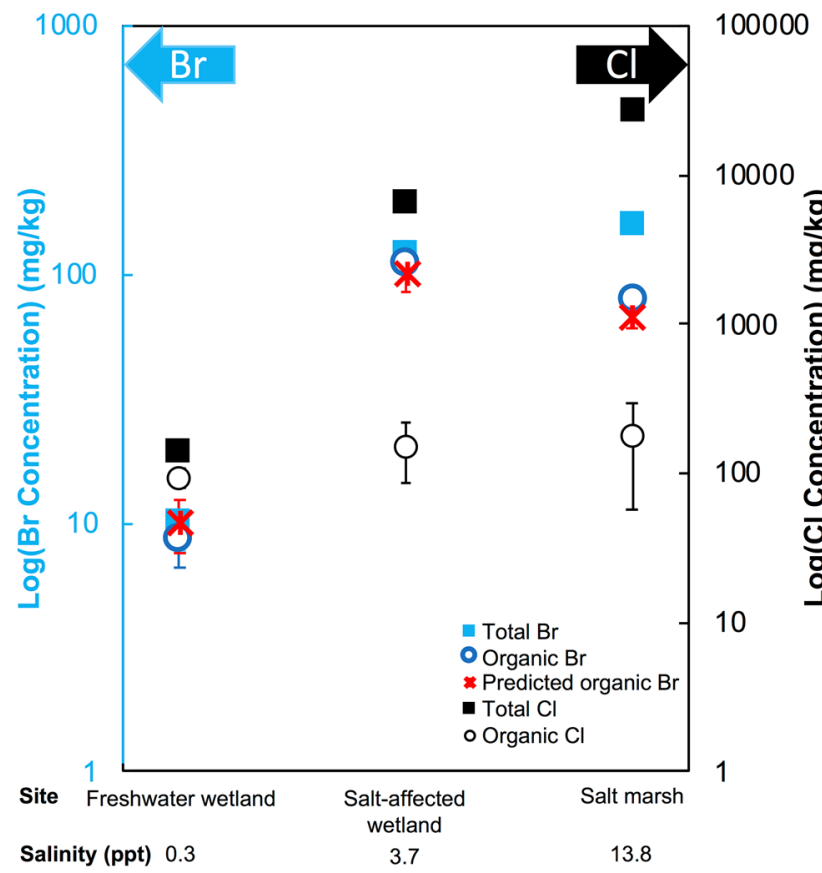

Figure 2 The concentration and speciation of $\mathrm{Br}$ (left, blue $\mathrm{y}$ axis) and $\mathrm{Cl}$ (right, black y axis) in sediments as a function of salinity ( $x$ axis) in Winyah Bay, South Carolina. All concentrations are the average of samples from different depths and two cores. Vertical error bars show the standard error and are in some cases smaller than the points. 

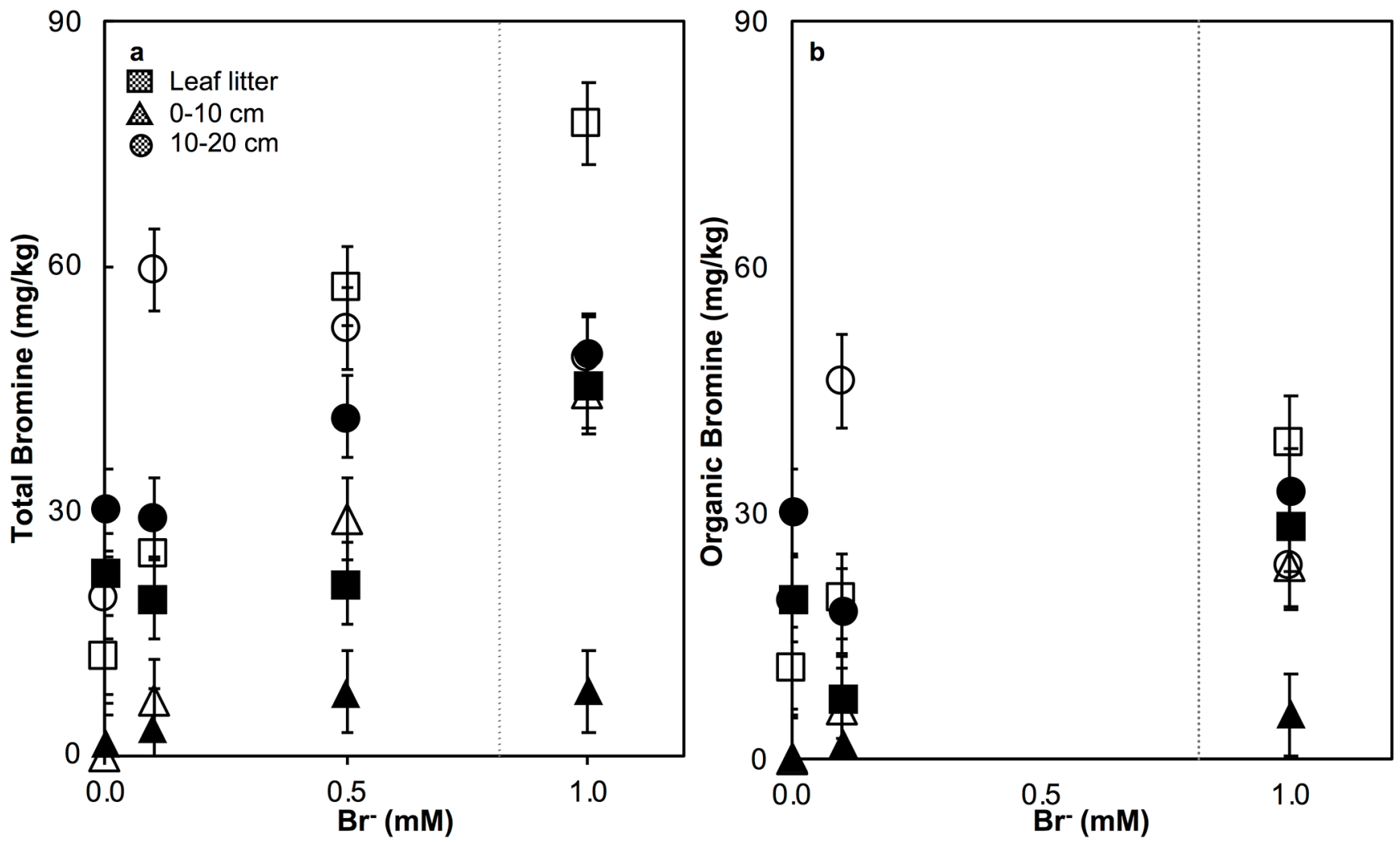

Figure 3 (a) Total $\mathrm{Br}$ and (b) organically bound $\mathrm{Br}$ produced in $\mathrm{Br}^{-}$-reacted soil samples as a function of increasing aqueous $\mathrm{Br}$ concentrations. Filled shapes $(\bullet)$ represent saturated conditions (mimicking salt marsh conditions) and open shapes (0) represent wet/ dry conditions (mimicking salt-affected wetland conditions). Vertical gray dotted line shows $\mathrm{Br}$ concentration in seawater in both panels. Error bars are based on replicate XRF analyses (total $\mathrm{Br}$ and organic $\mathrm{Br}$ ) and error from XANES linear combination fitting for organic Br.

exhibit similar weak sorption onto sediments, so the disproportionate retention of $\mathrm{Br}$ compared to $\mathrm{Cl}$ cannot be explained by differences in partition coefficients between sediment and water $\left(\mathrm{K}_{\mathrm{d}}\left(\mathrm{Cl}^{-}\right) \approx \mathrm{K}_{\mathrm{d}}\left(\mathrm{Br}^{-}\right)\right)$. The measured $\mathrm{K}_{\mathrm{d}}\left(\mathrm{Cl}^{-}\right)$is small and varies between 0.2 and 1.8 with the lowest values in the freshwater wetland (Table S-1). These differences in $K_{d}$ values are likely caused by differences in sediment characteristics (e.g., mineralogy, particle size, organic matter content) and depth averaged salinity values. However, the amounts of sorbed $\mathrm{Br}$ predicted using $\mathrm{K}_{\mathrm{d}}\left(\mathrm{Cl}^{-}\right)$are much smaller than the observed levels of $\mathrm{Br}_{\text {total }}$. The excess $\mathrm{Br}$ is likely retained in the sediment as $\mathrm{Br}_{\mathrm{org}}$, and the abundance of $\mathrm{Br}_{\text {org }}$ determined spectroscopically matches well with this calculated excess (measured $\mathrm{Br}_{\text {total }}$ - calculated sorbed Br') (Figs. 2 and S-4).

The concentration and speciation of sediment-bound $\mathrm{Cl}$ and $\mathrm{Br}$ differ significantly along the salinity gradient due to the geochemical differences between the halides and between these sites. In general, bromination of organic matter greatly exceeds chlorination. At all sites and all depths, the fraction of organically bound $\mathrm{Br}\left(\mathrm{Br}_{\text {org }} / \mathrm{Br}_{\text {total }}\right)$ is greater than the fraction of organically bound $\mathrm{Cl}\left(\mathrm{Cl}_{\text {org }} / \mathrm{Cl}_{\text {total }}\right)$ (Table S-1). This is likely because $\mathrm{Br}^{-}$is both more polarisable and less electronegative than $\mathrm{Cl}^{-}$, aiding organic molecule halogenation reactions, which are commonly electrophilic addition reactions (Butler and Walker, 1993; Leri and Myneni, 2012).

In addition, the high abundance of NOM (Table S-2) and its high aromaticity (Figs. S-5-S-7) likely support preferential bromination of NOM in the salt-affected wetland, even though the salinity at that site is much less than in the salt marsh. In the salt-affected wetland, salt water intrusion and increases in halide concentrations stress the freshwater plants, such as bald cypresses, and reduce their productivity, ultimately leading to forest dieback and conversion to salt marsh (Munns and
Tester, 2008; Chow et al., 2013; Neubauer, 2013). This adds a large amount of fresh plant biomass and NOM to the sediment (Table S-2), and ${ }^{13} \mathrm{C}$ NMR and FTIR spectroscopies of this NOM shows that it is rich in aromatic carbon when compared to other sites (Figs. S-5-S-7). Aromatic organic carbon is known to promote electrophilic addition of halides (Myneni, 2002; Leri and Myneni, 2012). The salt-affected wetlands also experience wet/dry conditions with seasons and thus promote extensive redox cycling of reactive Fe and Mn oxides, which are known in turn to promote halogenation reactions (Comba et al., 2015; Leri and Ravel, 2015; Lin et al., 2016). The loss of plant cover in these salt-affected wetlands may also promote photolytic reactions. In contrast to salt-affected wetlands, $\mathrm{Br}_{\text {org }}$ production is limited in freshwater wetlands by access to $\mathrm{Br}^{-}$ and in salt marshes by the low abundance of reactive NOM and permanent water-saturated conditions.

Laboratory experiments conducted on freshwater wetland sediments to simulate geochemical conditions in salt-affected wetlands (wet/dry cycles, relatively low salinity) and salt marshes (saturated conditions, relatively high salinity) reproduced the field observations and trends (Fig. 3). $\mathrm{Br}_{\text {total }}$ retained by sediments increased with exposure to elevated $\mathrm{Br}^{-}$ concentration in all samples rapidly (within hours). However, the samples exposed to wet/dry conditions, mimicking salt-affected wetland conditions, in general retained more $\mathrm{Br}_{\text {total }}$ and produced more $\mathrm{Br}_{\text {org }}$ than the samples exposed to saturated conditions, mimicking salt marsh conditions (Fig. 3). No consistent trend with depth is apparent, and elevated levels of $\mathrm{Cl}^{-}$and sample $\mathrm{pH}$ did not influence $\mathrm{Br}_{\text {org }}$ production significantly (Fig. S-8). Reactions of New Jersey soils with organic matter with $\mathrm{Br}^{-}$also produced extensive $\mathrm{Br}_{\text {org }}$ (Fig S-9). Organic matter in the New Jersey soils is derived from pine, maple, and oak, so its functional group composition is expected to differ from the Winyah Bay sediments, whose organic matter 


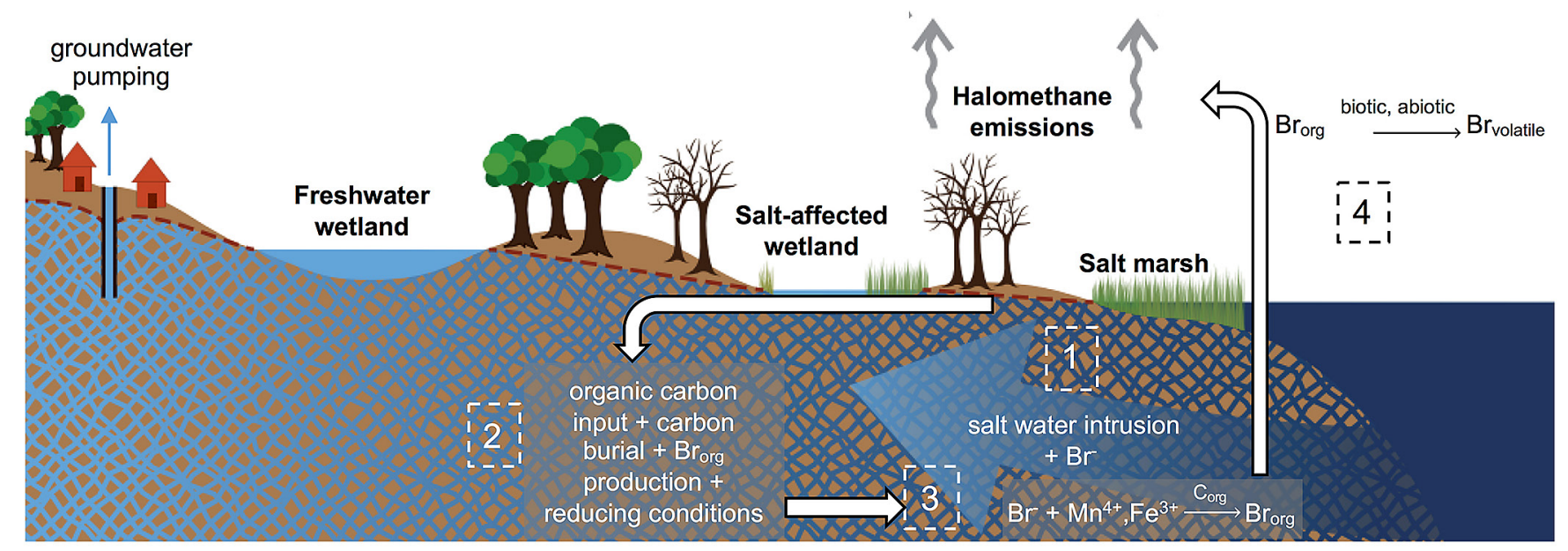

Figure 4 Schematic diagram showing organic carbon bromination and release of volatile organobromines occurring during coastal flooding by seawater. The reactions begin with seawater intrusion (1), followed by highly favourable $\mathrm{Br}_{\text {org }}$ production aided by geochemical conditions $(2,3)$, and ultimately the breakdown and release of this $\mathrm{Br}_{\text {org }}$ as volatile compounds into the atmosphere (4).

primarily derives from bald cypress, water tupelo, and swamp tupelo (Chow et al., 2013). In contrast to the Winyah Bay freshwater wetland sediments, the production of $\mathrm{Br}_{\text {org }}$ in the New Jersey soil is greater in the soil O-horizon, where the reactive NOM is more abundant, than in mineral-rich lower horizons. These results suggest that the extensive bromination observed in the Winyah Bay salt-affected wetland sediments is not unique to this site but rather may occur in many types of soils and sediments with varying sources of organic matter if they are affected by saltwater intrusion.

Both field and laboratory studies indicate that sedimentary NOM can be brominated when exposed to seawater Bromination of NOM is consistently favoured over chlorination, resulting in the accumulation of organobromines in sediments. Intrusion of salt water in coastal regions caused by sea level rise and extensive pumping of ground water exposes freshwater sediments and surface and subsurface soils to elevated salt levels (Fig. 4). This introduces $\mathrm{Br}^{-}$to aromatic-rich terrestrial $\mathrm{NOM}$, and $\mathrm{Br}_{\text {org }}$ production is likely to increase in all these environments (Fig. 4). The lability of this $\mathrm{Br}_{\text {org }}$ is unclear. Increased flooding of salt-affected wetlands by seawater increases sulphate concentrations, which stimulates microbial sulphate reduction and accelerates organic carbon decomposition and the microbially mediated reductive debromination of $\mathrm{Br}_{\text {org }}$ (Berg and Solomon, 2016). Thus, salt-affected wetlands are not a net source of methyl bromide (Wang et al., 2016; Jiao et al., 2018). However, salt marshes are a net source of methyl bromide (Wang et al., 2016; Jiao et al., 2018), and in the long term, the conversion of salt-affected wetlands into salt marshes with further sea level rise is ultimately likely to release $\mathrm{Br}_{\text {org }}$ retained in soil to the atmosphere as halomethanes. More work is needed to evaluate the timescale and extent of increased halomethane emissions due to sea level rise.

Our study documents for the first time that a large repository of $\mathrm{Br}_{\text {org }}$ forms from the reactions of seawater with terrestrial NOM and that the reactions are rapid, on the order of hours to days. Facilitated by changes in water salinity and fluctuating wet/dry seasonal cycles in coastal wetlands, bromination of NOM creates a potentially labile pool of organobromines. Further biotic and abiotic decomposition of NOM may break down these sediment-bound organobromines into either $\mathrm{Br}^{-}$(Jeong et al., 2011; Krzmarzick et al., 2012) or volatile halomethanes (Huber et al., 2009). The preferential production of organobromines is particularly problematic because $\mathrm{Br}$ radicals are an order of magnitude more efficient at destroying stratospheric ozone than $\mathrm{Cl}$ radicals (Daniel et al., 1999). As sea levels continue to rise, understanding both the formation and the breakdown of sediment-bound organohalogens may be crucial for predicting future changes in water quality in salt-affected wetlands and stratospheric ozone.

\section{Acknowledgements}

We thank Isaiah Ruhl and staff at the College of Science Major Instrument Cluster (COSMIC) at ODU for NMR analysis and Dr. Pat Hatcher for his assistance in analysing and interpreting NMR data. Thank you also to Aparna Raghu and Chris Habermann for help with the NJ soil study. We also thank the beamline scientists at the Stanford Synchrotron Radiation Lightsource, National Synchrotron Light Source, and Advanced Photon Sources, which all are supported by the Department of Energy, Office and Science, Office of Basic Energy Sciences. Finally, we thank Dr. Anne Morel-Kraepiel for reviewing the manuscript and providing critical comments. This work was funded by the National Science Foundation Geobiology program (award 1529927 to Clemson University and 1529956 to Princeton University) and Princeton University (Princeton Environmental Institute, Fred Fox Class of 1939 Fund, Office of the Dean of the College, and Department of Chemistry). Joe-Wong is supported by the Department of Defense through a National Defense Science and Engineering Graduate Fellowship and a Stanford Graduate Fellowship. Schlesinger is supported by a National Science Foundation Graduate Research Fellowship.

\section{Author Contributions}

Joe-Wong and Schlesinger contributed equally to the design and execution of experiments, analysis of the data, and to writing the manuscript and supplementary information. Myneni supervised the project and provided manuscript revisions and feedback. Chow assisted in monitoring of the field site and sample collection and provided input on the manuscript.

\section{Editor: Sophie Opfergelt}

\section{Additional Information}

Supplementary Information accompanies this letter at http:// www.geochemicalperspectivesletters.org/article1911. 


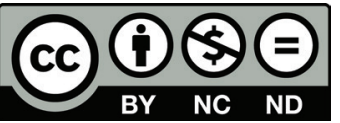

This work is distributed under the Creative Commons Attribution Non-Commercial No-Derivatives 4.0 License, which permits unrestricted distribution provided the original author and source are credited. The material may not be adapted (remixed, transformed or built upon) or used for commercial purposes without written permission from the author. Additional information is available at http://www.geochemicalperspectives letters.org/copyright-and-permissions.

Cite this letter as: Joe-Wong, C., Schlesinger, D.R., Chow, A.T., Myneni, S.C.B. (2019) Sea level rise produces abundant organobromines in salt-affected coastal wetlands. Geochem. Persp. Let. 10, 31-35.

\section{References}

BerG, R.D., SOlOMON, E.A. (2016) Geochemical constraints on the distribution and rates of debromination in the deep subseafloor biosphere. Geochimica et Cosmochimica Acta 174, 30-41.

Butler, A., Walker, J.V. (1993) Marine haloperoxidases. Chemical Reviews 93, 1937-1944

Chow, A.T., DAI, J., Conner, W.H., Hitchcock, D.R., WAng, J.-J. (2013) Dissolved organic matter and nutrient dynamics of a coastal freshwater forested wetland in Winyah Bay, South Carolina. Biogeochemistry 112, 571-587.

Comba, P., Kerscher, M., Krause, T., SchÖler, H.F. (2015) Iron-catalysed oxidation and halogenation of organic matter in nature. Environmental Chemistry 12, 381-395.

Daniel, J.S., Solomon, S., Portmann, R.W., Garcia, R.R. (1999) Stratospheric ozone destruction: The importance of bromine relative to chlorine. Journal of Geophysical Research: Atmospheres 104, 23871-23880.

Doyle, T.W., O’Neil, C.P., Melder, M.P.V., From, A.S., Palta, M.M. (2007) Tidal Freshwater Swamps of the Southeastern United States: Effects of Land Use, Hurricanes, Sea-level Rise, and Climate Change. In: Conner, W.H., Doyle, T.W., Krauss, K.W. (Ed.) Ecology of Tidal Freshwater Forested Wetlands of the Southeastern United States. Springer, Netherlands, 1-28.

GOÑI, M.A., THOMAS, K.A. (2000) Sources and transformations of organic matter in surface soils and sediments from a tidal estuary (North Inlet, South Carolina, USA). Estuaries 23, 548-564.

Hilton, T.W., NajJAR, R.G., Zhong, L., LI, M. (2008) Is there a signal of sea-level rise in Chesapeake Bay salinity? Journal of Geophysical Research: Oceans 113, C09002, doi: 10.1029/2007JC004247.

Huber, S.G., Kotte, K., Schöler, H.F., Williams, J. (2009) Natural Abiotic Formation of Trihalomethanes in Soil: Results from Laboratory Studies and Field Samples. Environmental Science \& Technology 43, 4934-4939.

JeOnG, H.Y., Anantharaman, K., Han, Y.-S., Hayes, K.F. (2011) Abiotic reductive dechlorination of cis-dichloroethylene by Fe species formed during iron-or sulfate-reduction. Environmental Science \& Technology 45, 5186-5194.

Jiao, Y., Ruecker, A., Deventer, M.J., Chow, A.T., Rhew, R.C. (2018) Halocarbon Emissions from a Degraded Forested Wetland in Coastal South Carolina Impacted by Sea Level Rise. ACS Earth and Space Chemistry 2, 955-967.

Krauss, K.W., Duberstein, J.A., Doyle, T.W., Conner, W.H., DaY, R.H., INABINETTE, L.W., WHITBECK, J.L. (2009) Site condition, structure, and growth of baldcypress along tidal/non-tidal salinity gradients. Wetlands 29, 505-519.

Krzmarzick, M.J., Crary, B.B., Harding, J.J., OYerinde, O.O., Leri, A.C., MYNEnI, S.C.B., NovAK, P.J. (2012) Natural Niche for Organohalide-Respiring Chloroflexi. Applied and Environmental Microbiology 78, 393-401.

Leri, A.C., Hay, M.B., Lanzirotti, A., RaO, W., Myneni, S.C.B. (2006) Quantitative Determination of Absolute Organohalogen Concentrations in Environmental Samples by X-ray Absorption Spectroscopy. Analytical Chemistry 78, 5711-5718.

LeRI, A.C., MYNENI, S.C.B. (2010) Organochlorine turnover in forest ecosystems: The missing link in the terrestrial chlorine cycle. Global Biogeochemical Cycles 24

Leri, A.C., MYneni, S.C.B. (2012) Natural organobromine in terrestrial ecosystems. Geochimica et Cosmochimica Acta 77, 1-10.
LeRI, A.C., RAVEL, B. (2015) Abiotic Bromination of Soil Organic Matter. Environmental Science \& Technology 49, 13350-13359.

Lin, K., Song, L., Zhou, S., Chen, D., GAN, J. (2016) Formation of brominated phenolic contaminants from natural manganese oxides-catalyzed oxidation of phenol in the presence of Br-. Chemosphere 155, 266-273.

MolinA, M.J., RowLAND, F.S. (1974) Stratospheric sink for chlorofluoromethanes: chlorine atom-catalysed destruction of ozone. Nature 249, 810-12.

Morrissey, E.M., Gillespie, J.L., Morina, J.C., Franklin, R.B. (2014) Salinity affects microbial activity and soil organic matter content in tidal wetlands. Global Change Biology 20, 1351-1362.

Munns, R., Tester, M. (2008) Mechanisms of Salinity Tolerance. Annual Review of Plant Biology 59, 651-681.

MYNENI, S.C.B. (2002) Formation of Stable Chlorinated Hydrocarbons in Weathering Plant Material. Science 295, 1039-1041.

Neubauer, S.C. (2013) Ecosystem Responses of a Tidal Freshwater Marsh Experiencing Saltwater Intrusion and Altered Hydrology. Estuaries and Coasts 36, 491-507.

Rhew, R.C., Miller, B.R., WeIss, R.F. (2000) Natural methyl bromide and methyl chloride emissions from coastal salt marshes. Nature 403, 292-295.

Titus, J.G., Richman, C. (2001) Maps of lands vulnerable to sea level rise: modeled elevations along the US Atlantic and Gulf coasts. Climate Research 18, 205-228.

Tuxen, K., Schile, L., Stralberg, D., Siegel, S., Parker, T., Vasey, M., Callaway, J., Kelly, M. (2011) Mapping changes in tidal wetland vegetation composition and pattern across a salinity gradient using high spatial resolution imagery. Wetlands Ecology and Management 19, 141-157.

WANG, J.-J., JiAO, Y., RHEW, R.C., CHOW, A.T. (2016) Haloform formation in coastal wetlands along a salinity gradient at South Carolina, United States. Environmental Chemistry 13, 745. 